revealed localized tumor with poor perivascular infiltrations.

Type 2.: early draining veins without any abnormal vascularities indicated increased perivascular infiltration. Two cases belonged to this group.

Type 3.: abnormal vascularities with early draining veins appeared on the angiograms, which strongly suggested increased infiltration of tumor cells. Two cases belonged to this group.

In our series intracranial reticulum cell sarcomas appeared to have two morphological growing patterns, 1) poorly vascularized, elastic hard mass and 2) perivascularly infiltrative growth without producing a mass. The hard mass is cool and the infiltrative growth is hot in angiographical appearances. These two patterns might be mixed. It is important that most of the reticulum cell sarcomas are rather avascular in angiographical appearances in spite of their high malignancy.

Intracranial reticulum cell sarcomas may be suspected if the developement of the tumor takes a very rapid course, and if characteristic angiographic appearances mentioned above with positive scinti-findings occur. Since reticulum cell sarcomas are highly malignant, their radiosensitivity is remarkably high. As soon as the diagnosis is established the patient should be treated with irradiation.

\title{
41. Primary Diffuse Meningeal Sarcomatosis
}

\author{
Tsuneo OHNo \\ Depertment of Neurosurgery, Kanto Rosai Hospital \\ Tetsuo Murai , \\ Central Clinical Laboratory, Pathalogical Division, \\ Kanto Rosai Hospital
}

Two autopsied cases of primary diffuse meningeal sarcomatosis were reported. These cases showed multiple radiculoneuropathy of cranial and spinal nerves with or without high intracranial pressure. Complete necropsy revealed that neoplastic cells of reticulum cell type accumulated diffusely in the subarachnoid space without any tumorous nodule in the craniospinal cavity. There were no tumors in other organs and leukemic diseases were denied.

Case 1: K. N., aged 21, male, was admitted on May 4, 1968, complaining of headache, double vision, motor weakness of both arms and staggering gait. Shortly after admission, he became drowsy with nuchal rigidity. Bilateral choked discs, bilateral oculomotor and left abducens weakness, and nystagmaus were found. The cerebrospinal fluid contained $40 \mathrm{mg}$. percent of protein, $50 \mathrm{mg}$. percent of glucose and $850 / 3$ cells which were similar to lymphocytes. The cerebral angiograms revealed unrolling of the anterior cerebral arteries and the basilar artery to be displaced forward against the clivus. There was the formainal sign of the posterior inferior cerebellar artery, too.

On may 22, he had cerebellar fits and transient respiratory arrest. Motor weak- 
Table 1 Cerebrospinal Fluid Findings of Case 2

\begin{tabular}{lcccccc}
\hline \multirow{2}{*}{ Date } & \multicolumn{2}{c}{1970} & & & 1971 \\
\cline { 2 - 6 } & Nov. 24 & Dec. 4 & Dec. 15 & Dec. 28 & Feb. 10 \\
\hline Initial Pressure $\mathrm{mmH}_{2} \mathrm{O}$ & 180 & 210 & 210 & 210 & 220 \\
\hline Queckenstedt & normal & normal & normal & normal & \\
\hline Xanthochromia & + & - & + & + & - \\
\hline Cell Count & $1,163 / 3$ & $1,732 / 3$ & $2,048 / 3$ & $3,086 / 3$ & $94 / 3$ \\
\hline Type of cells & $\begin{array}{l}\text { reticulum } \\
\text { cell type }\end{array}$ & R. C. type & R. C. type & $\begin{array}{l}\text { R. C. type } \\
\text { mitosis (++) }\end{array}$ & $\begin{array}{l}\text { R. C. type } \\
\text { with dest- } \\
\text { ructed cells }\end{array}$ \\
\cline { 2 - 6 } & 1,445 & 532 & 1,220 & 430 & \\
\hline Protein $\mathrm{mg} / 100 \mathrm{~m} l$ & 0 & 74 & 0 & 0 &
\end{tabular}

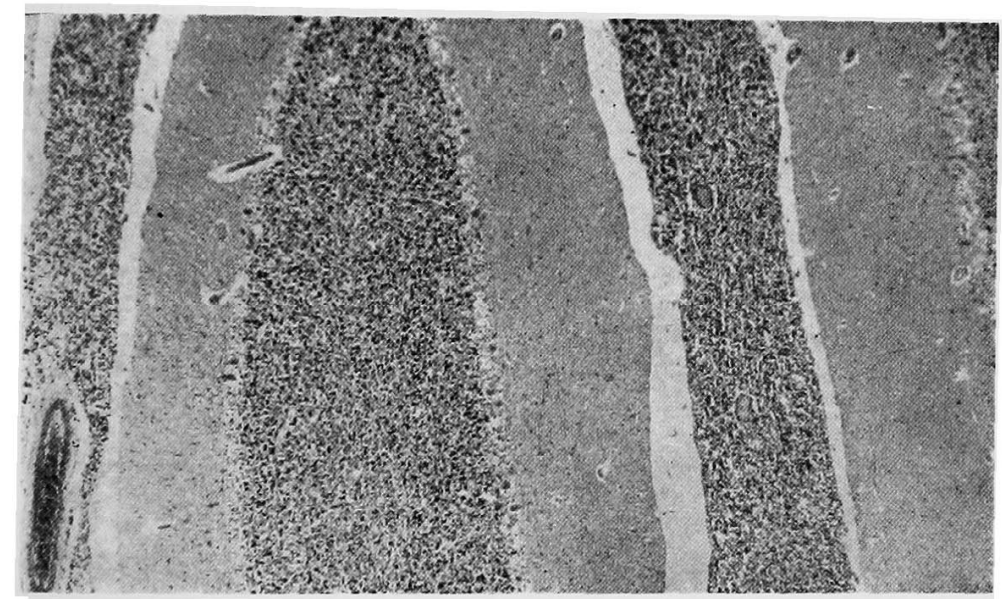

Fig. 1. Cerebellar Folia (Case 1.) Tumor cells fill the subarachnoid space between the cerebellar folia.

ness of all the extremities, dysphagia and dysphonia were progressing day by day.

On May 30, a suboccipital craniectomy with a laminectomy of the atlas was performed, but no tumor mass was found. Ten days after the operation, $\mathrm{Co}^{60}$ irradiation each consisting of $300 \mathrm{R}$ to the cerebellar region was begun, and a total of $5,100 \mathrm{R}$ was given.

Two weeks after the operation, improvement of consciousness was found, but dysphonia and dysphagia progressed gradually. Death came on July 5, 1968.

Necropsy.- It was evident that there were cloudy thickning of leptomeninges over the base of the brain and the cerebellar hemisphere, but not so marked. Microscopic examination revealed abundant accumulation of tumor cells in the sub- 


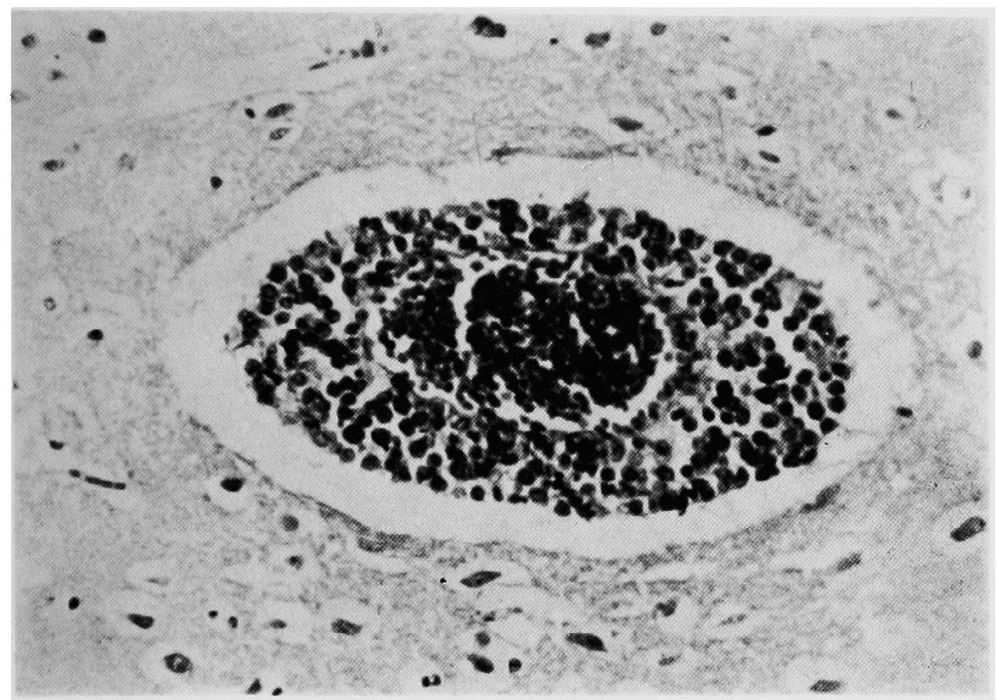

Fig. 4. Perivascular tumorous invasion around a penetrating arteriole of the brain tissue ("cuff-formation"). (Case 1.)

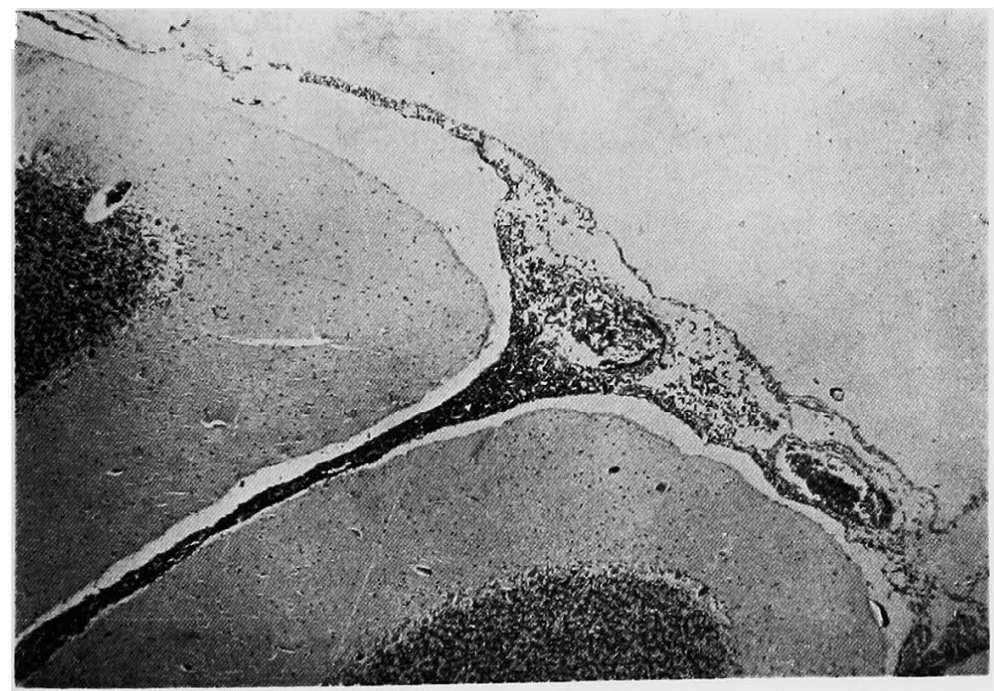

Fig. 5. Tumor cells of the subrachnoid space of the cerebellar folia. (Case 2.)

into brain forming cuffs around them (Fig. 4). On the contrary, no direct invasion of the neoplastic cells into cerebral parenchyma through pia was found, except in the pineal region. Dura mater was not involved.

The spinal cord could not be autopsied.

Case 2: I. N., aged 32, male, was admitted on Nov. 20, 1970, because of bilateral ptosis and dull pain of the low back. The ptosis suddenly began 2 days before the 


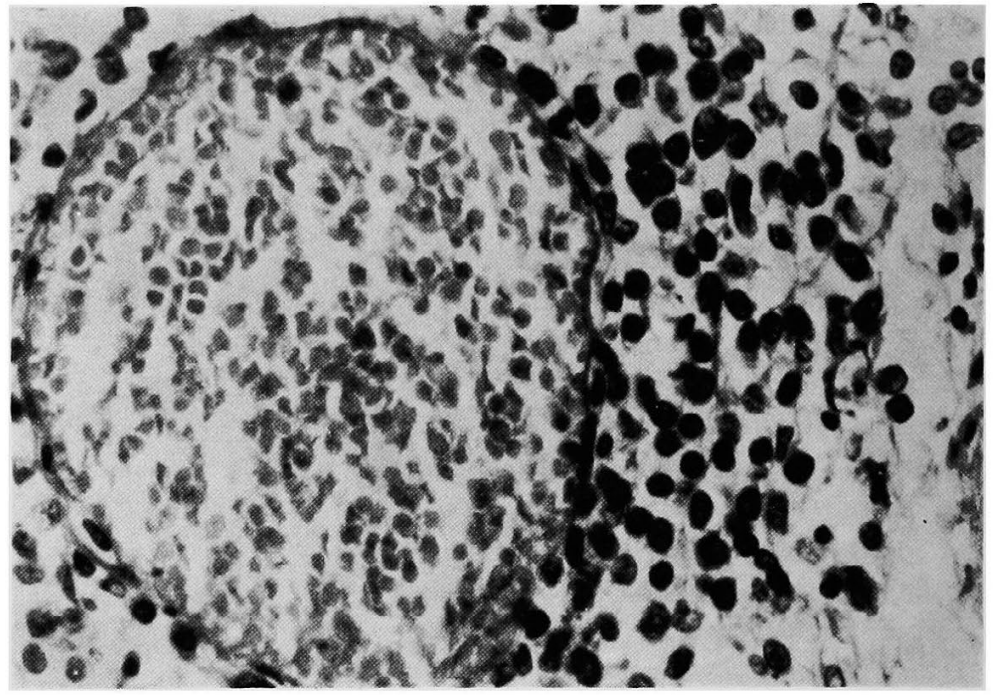

Fig. 2. The cells are round or ovoid with hyperchromatic nuclei and scanty cytoplasm. (Case 1.)

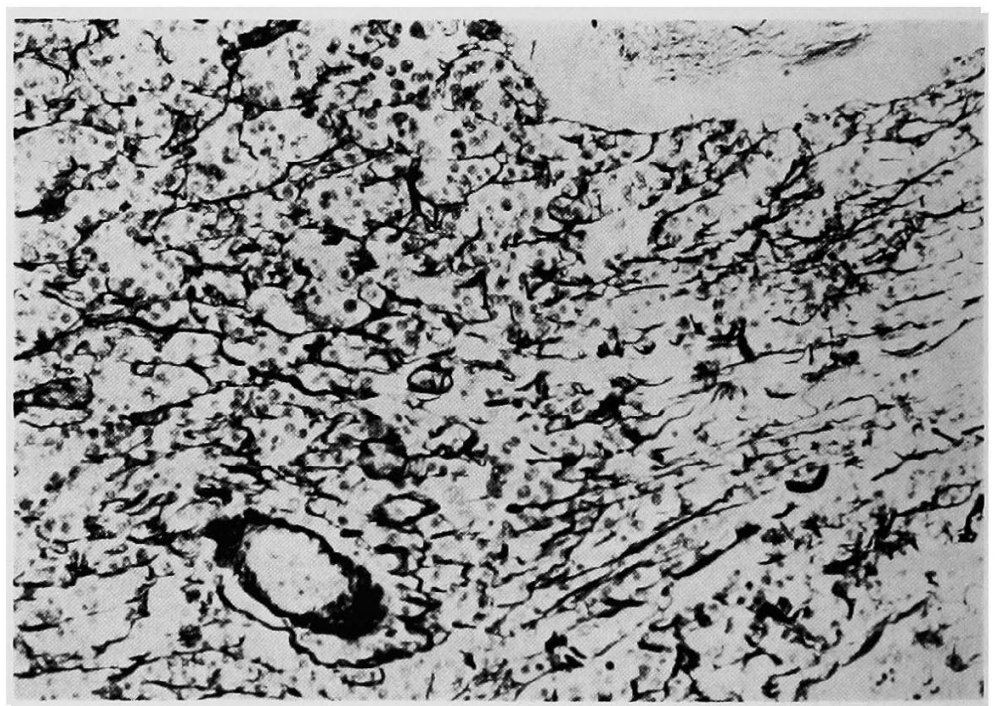

Fig. 3. There is abundant reticulum surrounding even individual tumor cells. (Case 1.)

arachnoid space (Fig. 1). The neoplastic cells were round or avoid with scanty cytoplasm and equal to twice the size of lymphocytes. The nuclei tended to be hyperchromatic with a heavy nuclear membrane (Fig. 2). Mitotic figures were easily found. Abundant networks of fine reticular fibrils were present among the cells (Fig. 3). The cells thickly surrounded some of the cranial nerves and followed along the vessels 


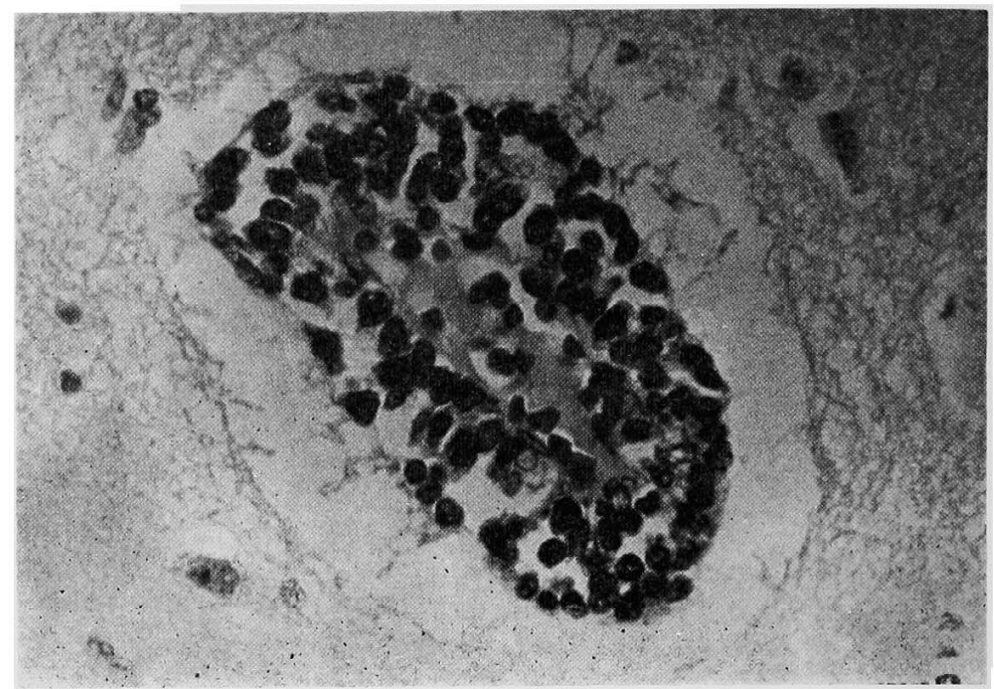

Fig. 6. Tumor cells of Case 2. in a Virchow-Robin space. These are similar to the cells of Case 1.

admission. Early in December, he had prickling pain with motor weakness of both lower extremities. The weakness rapidly progressed into complete paraplegia within 2 weeks after the onset. Urinary incontinence and weakness of the anal tonus developed. Soon after that, the flaccid paralysis occurred in some cranial cerves and upper extremities with causalgic and radiating pain.

Steroid therapy was given, but no effect was found.

All the rentgenologic studies revealed no positive findings. The cerebrospinal fluid contained numerous cells and high protein. The findings are listed in table $\mathrm{I}$.

The clinical diagnosis was multiple radiculo-neuropathy, possibly due to diffuse meningeal sarcomatosis.

On January 10, 1971, a systemic endoxan therapy was begun, but the signs gradually progressed. Muscle atrophy of face, chest and extremities became extremely evident. In mid-January right eye became blind and choked disc of left eye was found, so $\mathrm{Co}^{60}$ irradiation was given.

On Feb. 17, 1971, the patient died.

Necropsy.-In this case, there were no macroscopic abnormalities in brain and spinal cord. But microscopic examinations revealed that neoplastic cells accumulated in the subarachnoid space of the brain and high cervical spinal cord (Fig. 5). The cells looked just the same as those of case 1, however the degree of accumulation of the neoplastic cells were not so abundant (Fig. 6). Particularly, it was strange to say that there were little tumor cells found surrounding cranial nerves, spinal cord and nerve roots. It might be the result of strong anti-neoplasmic therapy, because the cell count in cerebraspinal fluid were $3,086 / 3$ on December 28, 1970, and then decreased to $94 / 3$ on Feb. 10, 1971. 